Proceedings of the 2018 International Scientific Conference 'Economic Sciences for Agribusiness and Rural Economy' No 1, Warsaw, 7-8 June 2018, pp. 98-102

\title{
THE GREY WATERFOOTPRINT OF CATTLE GRAZING: A CASE OF STUDY FOR ITALY
}

\author{
Vincenzo Allocca, PhD, Assistant Professor'; Elisabetta Marzano, PhD, Associate \\ Professor ${ }^{2}$; Miriam Tramontano, $\mathrm{PhD}^{3}$; Fulvio Celico, Full Professor ${ }^{4}$ \\ ${ }^{1}$ Department of Earth, Environmental and Resources Sciences, University of Naples Federico II \\ ${ }^{2,3}$ Department of Economic and Legal Studies, University of Naples 'Parthenope' \\ ${ }^{4}$ Department of Chemistry, Life Sciences and Environmental Sustainability, University of Parma
}

\begin{abstract}
Water footprint accounting has contributed to show that livestock production, and dairy production in particular, have a non-negligible impact in terms of freshwater appropriation (Palhares and Mezzopane, 2015). In this line of research, Allocca et al (2018) have contributed to the scientific debate pointing out that livestock grazing can have a substantial effect in terms of the environment-related grey water footprint $\left(G W F_{\text {env }}\right)$ originating from microbial contamination. However, cattle grazing can be a source of contamination also for chemical parameters, precisely nitrate, nitrite and ammonium. Albeit the microbial impact of cattle grazing has been documented by Allocca et al. (2018), they did not take into account possible consequences of the grazing activity in terms of chemical contamination, namely nitrates. This aspect is worth to be examined, since nitrates are important parameters to be evaluated when establishing guidelines for protecting aquatic life and/or ambient water quality for recreation use.
\end{abstract}

Keywords: grey water footprint, cattle grazing, microbial contaminant, karst aquifer, southern Apennines, Italy

JEL codes: Q25, Q26, Q57

\section{INTRODUCTION}

Mountain areas are source of important ecosystemic services; in southern Italy, karst Apennines reliefs are among the most important provider of ecosystemic services, and several regional parks have been established there to preserve their natural capital services.
Regulation of park areas establish severe restrictions to productive activities that can occur there. One of the allowed production is cattle grazing.

The main goal of this article is to demonstrate that the approach of preserving ecosystemic services by means of simple regulation might not be enough to guarantee a full preservation. Precisely, in this article

${ }^{1}$ Corresponding author: Via Cintia 21, 80126 Napoli, Italy, vincenzo.allocca@unina.it, +390 812535071

${ }^{2}$ Corresponding author: Via Generale Parisi 13, 80132 Napoli, Italy, marzano@uniparthenope.it, +390 815474333

${ }^{3}$ Corresponding author: Via Generale Parisi 13, 80132 Napoli, Italy, miriam.tramontano@uniparthenope.it, +390815474333

${ }^{4}$ Corresponding author: Parco Area delle Scienze 157/A, 43124 Parma, Italy, fulvio.celico@unipr.it, +390 521905348 
we examine the polluting impact of cattle grazing in karst environment, and we quantify its sustainability in terms of grey water footprint.

Following Allocca et al. (2018), we examine a case of study in a karst environment. Water uses documented in the area of study refer to in-stream uses, namely cattle grazing and recreational activities such as picnicking by the stream, that can be easily extended to other environment with similar geological characteristics. Differently from the evidence provided by Allocca et al. (2018), here we show that when chemicals contamination is taken into account, the recreational fruition of the study area can be at risk in presence of cattle grazing.

\section{THEORETICAL BACKGROUND}

It is widely acknowledged that livestock farming is among the major anthropogenic sources of inorganic nitrogen in aquatic ecosystems along with the use of animal manure as fertilizer. As to this latter, Seeling and Nowatzki (2001) recommend as a good management practice, to use dry manure in sandy or gravelly soils that overlay shallow groundwater, because $\mathrm{NO}_{3}$ dissolved in water can readily leach through the soil profile into groundwater. However, a less debated topic is the effect of nitrogen leaching originated by cattle grazing. In waterfootprint literature, grazing systems, compared to conventional farming, have a lower impact in terms of direct water footprint related to the service water consumed (Mekonnen and Hoekstra, 2012). As a matter of fact, existing water footprint (WF) accounting for livestock finds the main contribution from the green component of WF (Mekonnen and Hoekstra, 2012; Gerbens-Leenes, Hoekstra and Mekonnen, 2014), with the grey component taking a negligible measure. When coming to studies focusing on dairy production systems the grey component becomes important, especially for its possible impact in terms of eutrophication (Palhares and Mezzopane, 2015).

The present research starts from the evidence provided by Allocca et al. (2018) as regards to the environment-related grey waterfootprint $\left(G W F_{\text {env }}\right)$ of cattle grazing in karst environment, precisely in the study area Acqua della Madonna, Terminio mount, southern Italy. Differently from previous literature that has investigated the waterfootprint of livestock, suggesting that cattle grazing has a limited impact in terms of grey waterfootprint, Allocca et al. (2018) find that there is a non-negligible effects due to microbial contamination, precisely fecal coliforms. In addition to a methodological contribution as concerning the animal footprint, the $G W F_{\text {env }}$ examined by Allocca et al. (2018) has the implication of rising valuable recommendations to local authorities a in order to preserve the bacterial quality of groundwater in the karst study area of the Picentini Mounts Regional Park.

\section{MATERIALS AND METHODS}

\section{The study area and data}

The Acqua della Madonna test site (Campania, southern Italy) lies at an altitude of about 1,200 $\mathrm{m}$ a.s.1. in the central sector of the Mt. Terminio karst aquifer and the Picentini Regional Park. The site holds a compartmentalised karst groundwater body, feeding several high-altitude springs. The sub-basin of spring S2 (Fig. 1) is of prime interest for this study, since it contains a small endorheic karst plain where grazing occurs.

Daily precipitation were recorded by a meteorological station for the period from September 2001 to October 2002. For the same period, the discharge of spring S2 was measured weekly or daily by means of a flow meter (SIAP-MICROS Inc., Italy). All the discharge measurements were taken at the outlet of the spring. Water samples for chemical analyses were collected weekly or daily at spring $\mathrm{S} 2$ to measure the concentration of nitrate and nitrite $(\mathrm{mg} / \mathrm{l})$.

\section{Environment-related grey water footprint}

Environment-related grey water footprint $\left(G W F_{\text {env }}\right)$ represents virtual water needed to absorb the contamination loading originating from cattle grazing. Of course, to calculate the $G W F$ in general, and the $G W F_{\text {env }}$, in particular, it is necessary to establish which pollutant is under consideration. In our case we consider $\mathrm{NO}_{2}$ (nitrite). Thanks to intensive monitoring of water volumes and pollution concentrations, 


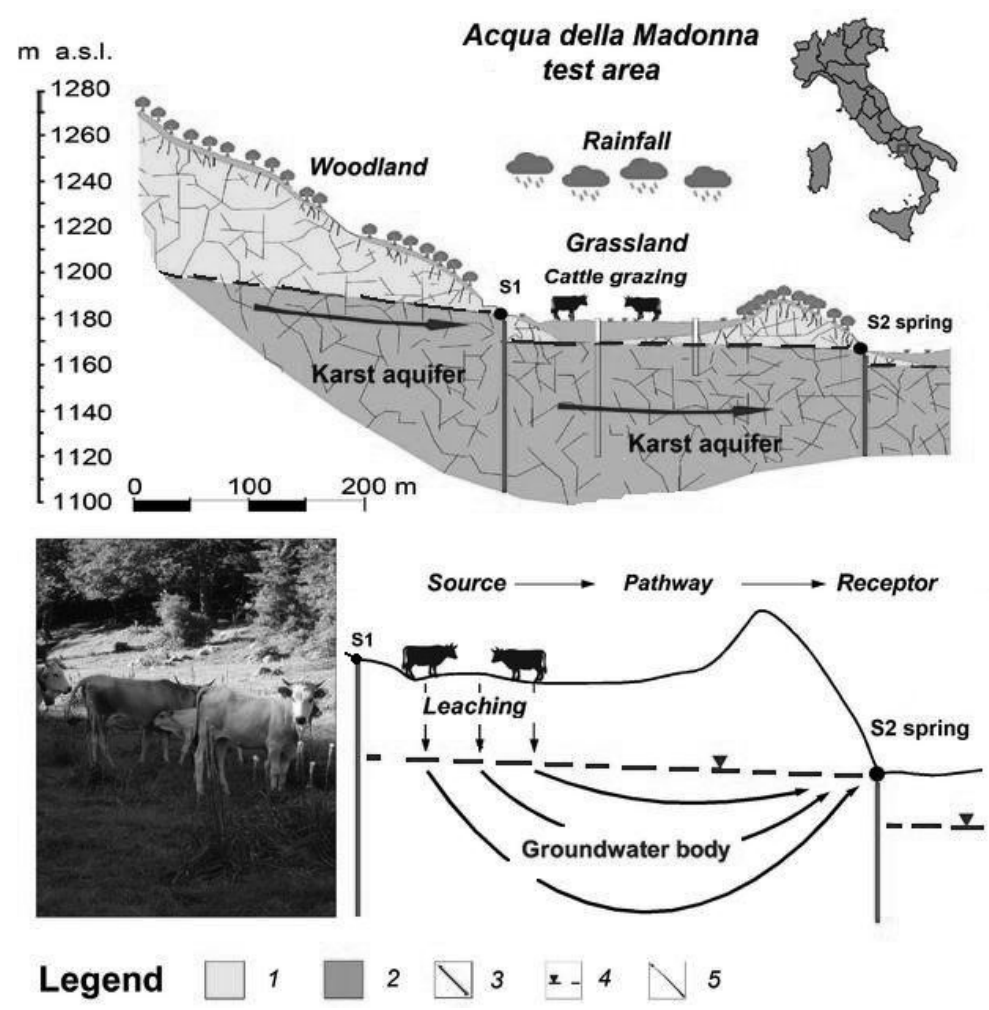

Figure 1. Hydrogeological section of Acqua della Madonna test area and source-pathway-receptor conceptual model for the mechanism of chemical contamination of the groundwater body and S2 spring: 1 - limestone karst aquifer; 2 - pyroclastic-fall deposits; 3 - faults; 4 - water table level; 5 - groundwater flow direction

Source: Allocca et al. (2018, modified).

we can measure $G W F_{e n v}$ directly from the observed volume of freshwater flowing during the period of contamination. Adapting the modelling of the environment-related grey water footprint recommended by Allocca et al. (2018), we get:

$$
G W F_{e n v}=\frac{Q_{(1 / \mathrm{s})}^{*}\left(\sum_{j=t}^{T} N_{j(\mathrm{mg} / \mathrm{l})}\right) / T}{\left(N_{\max }-N_{n a t}\right)_{\mathrm{mg} / 1}}(1 / \mathrm{s})
$$

where:

$Q^{*}$ - average level of nitrite measured during the interval of contamination;

$t$ - the first week of contamination, that is the first week during which the concentration of nitrite $N_{j}$ exceeds the threshold $N_{\max }$;

$T$ - the last week of observed contamination.
For this study we adopt as maximum acceptable concentration the standard provided by the $G W F$ guidelines $0.06 \mathrm{mg} / 1$, which is based on the guideline for the protection of aquatic life as proposed by the Canadian Council of Ministers of the Environment. As to the level of natural concentration of nitrite, $N_{\text {nat }}$, it has been set to $0.01 \mathrm{mg} / \mathrm{l}$.

\section{RESULTS AND DISCUSSION}

If we compare two different periods for which we have a daily monitoring, late 2001 and mid-2002, we get the idea of which are the drivers of chemical contamination: effective rainfall and discharge. The higher the discharge, the more chemical contamination is detected in the water sampled (Fig. 2). In both periods, cattle grazing was absent, however, from the 
Proceedings of the 2018 International Scientific Conference 'Economic Sciences for Agribusiness and Rural Economy' No 1, Warsaw, 7-8 June 2018, pp. 98-102
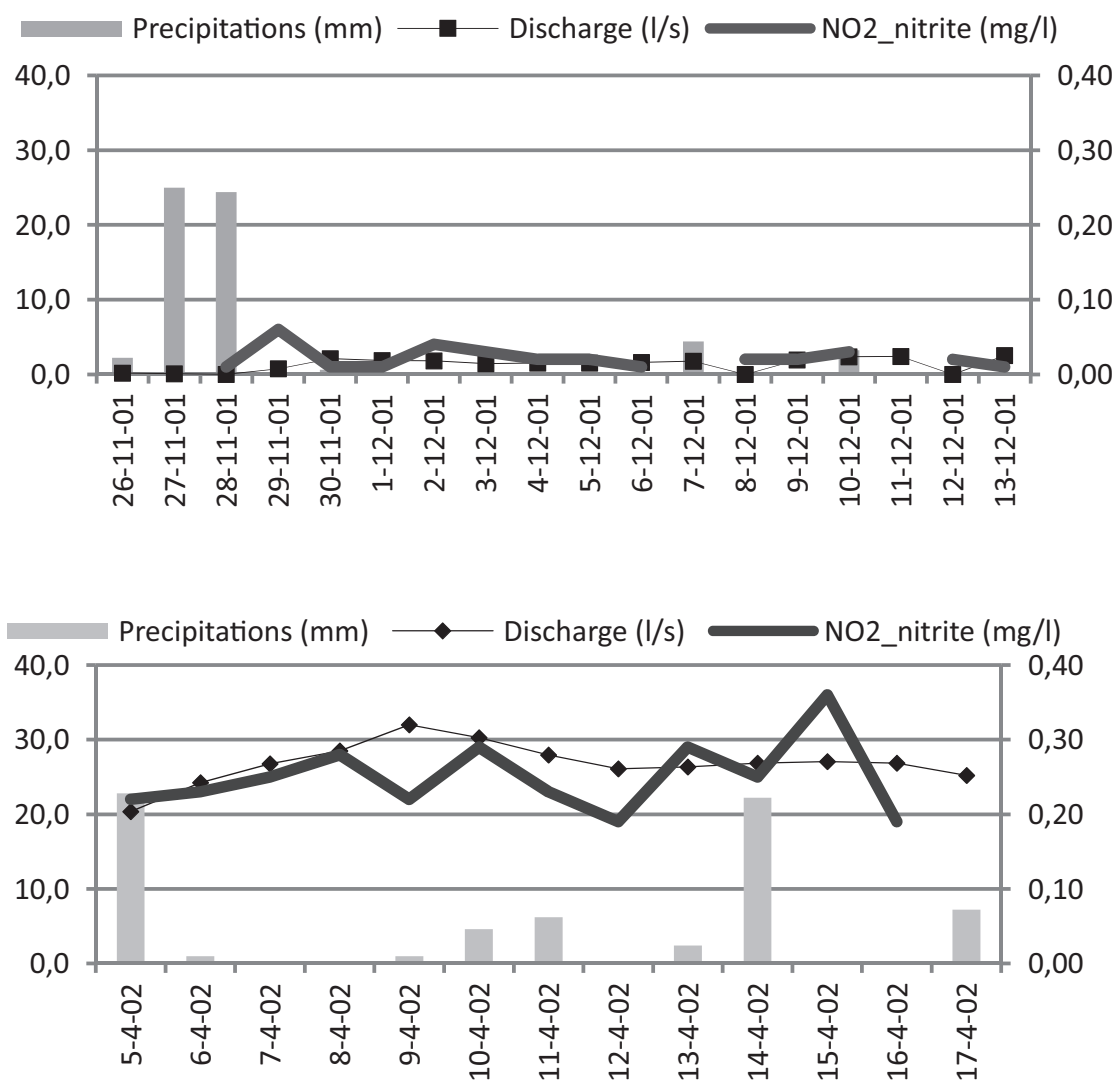

Figure 2. Nitrites contamination at spring S2 (right axis), precipitation and S2 spring discharge (left axis). Interval of monitoring: top graph November 2001; bottom graph April 2002

Source: author's monitoring and Allocca et al. (2008).

Table 1. Environment-related grey water footprint accounting

\begin{tabular}{|l|c|c|c|c|c|c|}
\hline Specification & Episode 1 & Episode 2 & Episode 3 & Episode 4 & Episode 5 & Total \\
\hline Discharge (1/s) & 0.321 & 0 & 0.752 & 25.6 & 14.0 & - \\
\hline Nitrate $(\mathrm{mg} / \mathrm{l})$ & 0.22 & 0.17 & 0.06 & 0.20 & 0.61 & - \\
\hline Duration (weeks) & 01 & 01 & 01 & 08 & 01 & 12 \\
\hline$G W F_{\text {env }}\left(\mathrm{m}^{3} / \mathrm{cattle}\right)$ & 2.85 & 0 & 1.82 & 1683 & 342.4 & 2030 \\
\hline
\end{tabular}

Source: authors' monitoring and Allocca et al. (2008).

data presented on the bottom graph we see that $\mathrm{NO}_{2}$ contamination is quite high, and above the $0.6 \mathrm{mg} / 1$ concentration (the ambient water quality standard recommended by Franke, Boyacioglu and Hoekstra, 2013), whereas in the top panel either discharge and chemical concentration are flat in proximity of zero contamination.

By appropriately using Equation (1) to measure the $G W F$, we get the following Table 1, where the estimated $G W F$ amounts to about $2,030 \mathrm{~m}^{3}$ per unit of cattle. 


\section{CONCLUSIONS}

The local authority of the Picentini Mounts Regional Park (one of the largest Regional Parks in Italy), once aware of these water footprint accounts, would be faced with the need to intervene to control the negative effect that cattle grazing ingenerates on water quality. Since in-stream actions can affect and be affected by water quality, in the case of study the ambient quality of water is the relevant measure to take into account. This evidence also suggest that the approach of preserving ecosystemic services by means of simple regulation might not be enough to guarantee a full preservation. A very simple and easy to adopt policy to preserve ambient quality of water is to introduce restrictions to cattle grazing, imposing cleaning activity of the endorheic plane.

\section{Acknowledgements}

Vincenzo Allocca acknowledges financial support from Department of Earth, Environmental and Resources Sciences, University of Naples Federico II (Departmental Research, 2018). Elisabetta Marzano acknowledges financial support from University of Naples 'Parthenope' (Research Programme, 2016-2018). Usual disclaimers apply.

\section{REFERENCES}

1. Allocca, V., Celico, F., Petrella, E., Marzullo, G., Naclerio, G. (2008). The role of land use and environmental factors on microbial pollution of mountainous limestone aquifers. Environmental Geology, 55, pp. 277-283.

2. Allocca, V., Marzano, E., Tramontano, M., Celico, F. (2018). Environmental impact of cattle grazing on a karst aquifer in the southern Apennines (Italy): quantification through the grey water footprint. Ecological Indicators, 93, pp. 830-837.

3. Franke, N.A., Boyacioglu, H., Hoekstra, A.Y. (2013). Grey water footprint accounting: Tier 1 supporting guidelines. Value of Water Research Report Series 65. UNESCO-IHE, Delft.

4. Gerbens-Leenes, P.W., Hoekstra, A.Y., Mekonnen, M.M. (2013). The water footprint of poultry, pork and beef: A comparative study in different countries and production systems. Water Resources and Industry, 1-2, pp. 25-36.

5. Mekonnen, M.M., Hoekstra, A.Y. (2012). A Global Assessment of the Water Footprint of Farm Animal Products. Ecosystems, 15, pp. 401-415.

6. Palhares, J.C.P., Pezzopane, J.R.M. (2015). Water footprint accounting and scarcity indicators of conventional and organic dairy production systems. Journal of Cleaner Production, 93, pp. 299-307.

7. Seeling, B., Nowatzki, J. (2001). Working to avoid nitrogen contamination. North Dakota State University, Extension Series Publications, AE Series 1218, December.

8. Seeling, B., Nowatzki, J. (2017). Water quality and nitrogen. North Dakota State University, Extension Series Publications, AE Series 1216, June.

9. Weston, D., Seeling, B. (1994). Managing nitrogen fertilizer to prevent groundwater contamination. North Dakota State University, Extension Series Publications, EB Series 64. 